\title{
Comparing Adult Males and Females in the United States to Examine the Association between Body Mass Index and Frequent Mental Distress: An Analysis of Data from BRFSS 2011
}

\author{
Soumyadeep Mukherjee \\ Department of Epidemiology, Robert Stempel College of Public Health \& Social Work, Florida International University, \\ 11200 University Park, AHC 595-1, 11200 SW 8th Street, Miami, FI 33199, USA
}

Correspondence should be addressed to Soumyadeep Mukherjee; smukh004@fiu.edu

Received 11 August 2013; Accepted 23 September 2013

Academic Editor: Benno Roozendaal

Copyright (C) 2013 Soumyadeep Mukherjee. This is an open access article distributed under the Creative Commons Attribution License, which permits unrestricted use, distribution, and reproduction in any medium, provided the original work is properly cited.

Background. There is conflicting evidence regarding the association of body mass index (BMI) with mental distress. Studies have focused on different dimensions of mental health and used different definitions and many of them have not controlled for confounding factors. The aim of this study was to examine the relationship between frequent mental distress (FMD) and BMI among adults in the United States, with special emphasis on gender differences. Methods. Data from the Behavioral Risk Factor Surveillance System (BRFSS) for the year 2011 were used in logistic regression models to predict FMD, defined as having 14 or more days of poor mental health in the previous month. Sociodemographic factors, tobacco and alcohol use, diet and physical activity, and number of chronic diseases were controlled for. Results. $11.95 \%(n=53,715)$ of the participants with valid responses $(n=496,702)$ had FMD. The adjusted ORs of having FMD among underweight, overweight, and obese females were 1.13 (95\% CI: 1.10, 1.60), 1.10 (95\% CI: 1.03, 1.19), and 1.21 (95\% CI: 1.13, 1.31), respectively, but they were not statistically significant for males. Conclusions. These findings suggest a relationship between BMI and FMD, independent of other variables. It may be useful to explore longitudinal trend in this association.

\section{Introduction}

Mental illness is a term used to describe "health conditions that are characterized by alterations in thinking, mood, or behavior (or some combination thereof) associated with distress and/or impaired functioning" [1]. In any particular year, approximately $25 \%$ of all adults (people aged 18 and above) in the United States (U.S.) have mental illness with an economic burden of about 300 billion U.S. dollars [2]. Almost half of all U.S. adults will be affected by at least one mental illness during their lifetime [3]. One of the ways to estimate the burden of mental illness is by looking at frequent mental distress (FMD), that is, having 14 or more days of poor mental health in the previous 30 days [4]. Poor mental health, which includes stress, depression, and problems with emotions, is ascertained by the subjective appraisal of one's own mental status [5]. In addition to its impact on quality of life [6], mental distress is associated with suicidal ideation and attempts [7] and chronic conditions, such as diabetes, cardiovascular disease, and cancer [8]. Harmful behaviors, such as physical inactivity, engaging in risky sexual behaviors, violence, and substance use, are related to mental distress [9-11]. A less certain area is the association of body mass index (BMI) with mental health; while some studies have reported an association [12, 13], others did not find any such evidence [14, 15]. BMI, calculated as weight $(\mathrm{kg}) /[\text { height }(\mathrm{m})]^{2}$, is the basis for classifying adults as underweight (BMI: below 18.5), normal (BMI: 18.5-24.9), overweight (BMI: 25.0-29.9), and obese (BMI: 30.0, and above) [16].

Although precise mechanisms are not clear [17], common underlying genetic factors [18] and biophysiological mechanisms [19] are implicated behind the relationship of obesity with poor mental health. Stigma and discrimination associated with being obese and overweight can lead to mental health consequences $[20,21]$. Body image, which is 
the psychological experience of the appearance and function of one's own body and an aspect of the person's mental representation of himself/herself [22], partially explains the relationship between obesity and mental distress [23]. SelfDissatisfaction with weight is more common among women than men [24] and especially among white women compared with black women [25]. Sociodemographic factors, physical activity, and nutrient intake might influence the relationship between BMI and psychological distress $[26,27]$.

In 2007, obese men and overweight or obese women in the United States had a significantly higher prevalence of serious psychological distress, compared with people having normal BMI [28]. Serious psychological distress, unlike FMD, is an estimate of serious mental illness and has a lower prevalence $[29,30]$. Certain subgroups within the obese population [31], those seeking treatment to lose weight $[32,33]$ and bingeeaters, might be more prone to psychological problems. Some studies have not found any association between BMI and mental distress; some others have reported that mental distress decreases with an increase in BMI [14, 34-36].

Fewer studies have investigated the relationship between being underweight and mental health, with evidence supporting $[28,37]$ as well as refuting [38]. While investigating the association of low BMI and mental distress, confounding factors like being unmarried, unemployed, or disabled should be considered [39-41].

The evidence is inconclusive regarding an association between BMI and mental distress. Different studies have focused on different dimensions of mental health, used different definitions of mental illness, and studied different populations and many of them have not controlled for all the potential confounding factors. The primary aim of this study was to explore the association between FMD and BMI in a representative sample of U.S. adults included in the Behavioral Risk Factor Surveillance System (BRFSS) dataset of 2011. The secondary aim was to examine whether this association differed between males and females. The hypothesis was that people who do not have a normal BMI are more likely to suffer from FMD than those in the normal BMI category, even after adjusting for all the covariates.

\section{Methods}

2.1. Study Population. This study is based on the analysis of 2011 BRFSS results. BRFSS, the principal health-related telephone survey among a representative sample of U.S. residents aged 18 years and above, collects information about the respondents' risk behaviors and events affecting health, chronic health conditions, and use of preventive services. A total of more than 506,000 interviews were conducted in 2011 [42].

2.2. Measuring FMD. The BRFSS questionnaire has an item asking the respondent to report the number of days his/her mental health was not good in the previous 30 days [43]. All the participants who had 14 or more days of "not good" mental health in the previous month were categorized as having FMD [4] and the rest were categorized as not having FMD.
2.3. Independent Variables. The variable categorizing individuals based on their BMI was the main predictor for this analysis. Age categories in years, gender, race/ethnicity, level of education completed, employment status, income level, and marital status were the sociodemographic covariates. Tobacco and alcohol use were considered. Other lifestyle factors included were number of healthy food items and physical activity. The number of obesity related chronic conditions was taken into account, depending on whether a health professional ever told them of having high blood pressure, high cholesterol, heart disease, stroke, asthma, diabetes, or arthritis.

2.4. Statistical Analyses. The respondents who answered as "don't know/not sure," "refused," or had missing responses at random were excluded from the analyses. Women who reported being told of having high blood pressure and/or diabetes only during their pregnancy were also excluded. Logistic regression analysis was used to investigate the association of FMD with BMI and other covariates. Each of the independent variables was separately used to predict FMD. This was followed by a multivariable model, where all the variables were simultaneously introduced. Finally, separate multivariable analyses were performed after stratifying for gender. All the independent variables were categorical, except the number of healthy food items (0-4) and number of everdiagnosed chronic conditions (0-6), which were treated as continuous in multivariable analysis. All analyses were performed using SAS statistical software package, version 9.3 (SAS Institute Inc., Cary, North Carolina). Adjustments were made for the sampling design and for the raking procedure used to assign respondent weights [44] by using "proc survey" procedures in SAS [45].

\section{Results}

3.1. Characteristics of the Sample. There were 198812 males (weighted percentage: $48.73 \%$, 95\% CI: 48.44\%, 49.02\%) and 307655 females (weighted percent: $51.27 \%$, 95\% CI: 50.98\%, $51.56 \%$ ) in the BRFSS 2011 sample (Table 1). Most of the respondents were non-Hispanic Whites (weighted percent: $66.42 \%$ ). $1.87 \%, 35.85 \%$, and $27.42 \%$ of the sample were underweight, overweight, and obese, respectively. Overall prevalence of frequent mental distress (FMD) was $10.8 \%$, with a weighted percentage of $11.95 \%$ (95\% CI: 11.75\%, 12.14\%).

3.2. Bivariate Analysis Results. From Table 2, females were 1.4 times likely to report FMD compared to males (OR: 1.39, 95\% CI: 1.34, 1.44). Non-Hispanic Asians had lower odds (OR: $0.50,95 \%$ CI: $0.42,0.60)$, but people of all the other races had significantly higher odds of reporting FMD compared to non-Hispanic Whites. Participants who graduated from high school and those who had higher education were significantly less likely to suffer from FMD. Compared to people who were employed for wages, participants who were out of work for more than 1 year (OR: 3.20, 95\% CI: 2.94-3.49), out of work for less than 1 year (OR: 2.66, 95\% CI: 2.41-2.93), homemaker (OR: 1.31, 95\% CI: 1.21-1.42), student (OR: 1.32, 95\% CI: 
TABLE 1: Distribution of the sample of adults in the United States, BRFSS 2011 by few sociodemographic factors, BMI, and FMD.

\begin{tabular}{|c|c|c|c|c|}
\hline Variable & Categories & Number of respondents ${ }^{\mathrm{a}}$ & Weighted \% & $95 \% \mathrm{CI}$ \\
\hline \multirow{6}{*}{ Age category (years) } & $18-24$ & 23069 & 12.88 & $12.63-13.14$ \\
\hline & $25-34$ & 49621 & 17.65 & $17.40-17.89$ \\
\hline & $35-44$ & 65487 & 17.56 & $17.34-17.79$ \\
\hline & $45-54$ & 92177 & 18.87 & 18.66-19.09 \\
\hline & $55-64$ & 115569 & 15.46 & $15.29-15.63$ \\
\hline & $\geq 65$ & 160544 & 17.58 & $17.42-17.74$ \\
\hline \multirow{2}{*}{ Gender } & Males & 198812 & 48.73 & $48.44-49.02$ \\
\hline & Females & 307655 & 51.27 & $50.98-51.56$ \\
\hline \multirow{6}{*}{ Race and ethnicity } & Non-Hispanic White & 396273 & 66.42 & $66.13-66.71$ \\
\hline & Black non-Hispanics & 41056 & 11.22 & $11.02-11.42$ \\
\hline & Asian non-Hispanic & 9492 & 3.93 & $3.78-4.08$ \\
\hline & American Indian/Alaska Native non-Hispanic & 7088 & 1.08 & $1.02-1.13$ \\
\hline & Hispanic & 38764 & 15.18 & $14.94-15.43$ \\
\hline & Other race non-Hispanic & 13794 & 2.17 & $2.08-2.25$ \\
\hline \multirow{4}{*}{ Education } & Did not graduate from high school & 46423 & 15.42 & $15.17-15.67$ \\
\hline & Graduated from high school & 149387 & 29.22 & $28.96-29.49$ \\
\hline & Attended college or technical school & 136060 & 29.98 & $29.72-30.25$ \\
\hline & Graduated from college or technical school & 172669 & 25.38 & $25.16-25.60$ \\
\hline \multirow{8}{*}{ Employment status } & Employed for wages & 207193 & 47.25 & $46.96-47.54$ \\
\hline & Self-employed & 40212 & 7.84 & $7.68-7.99$ \\
\hline & Out of work for $>1$ year & 17129 & 4.80 & $4.66-4.93$ \\
\hline & Out of work for $<1$ year & 13971 & 4.37 & $4.23-4.51$ \\
\hline & Homemaker & 35353 & 6.96 & $6.82-7.09$ \\
\hline & Student & 11435 & 5.83 & $5.65-6.02$ \\
\hline & Retired & 142070 & 16.39 & $16.23-16.55$ \\
\hline & Unable to work & 142070 & 6.56 & $6.43-6.70$ \\
\hline \multirow{4}{*}{ BMI category } & Normal & 163451 & 34.86 & $34.57-35.14$ \\
\hline & Underweight & 8279 & 1.88 & $1.79-1.96$ \\
\hline & Overweight & 173661 & 35.85 & $35.56-36.13$ \\
\hline & Obese & 133116 & 27.42 & $27.16-27.68$ \\
\hline \multirow{2}{*}{ FMD } & Yes & 53715 & 11.95 & $11.75-12.14$ \\
\hline & No & 442987 & 88.05 & $87.86-88.25$ \\
\hline
\end{tabular}

BMI: body mass index; CI: confidence interval; FMD: frequent mental distress; OR: odds ratio.

${ }^{\mathrm{a}}$ The total number of respondents for the variables differs because of unequal number of missing values.

1.18-1.48), and unable to work (OR: 7.31, 95\% CI: 6.897.75) had significantly higher odds of suffering from FMD. However, retired individuals had lower odds (OR: 0.84, 95\% CI: 0.79-0.89) of reporting FMD. Those in the annual income categories higher than $15,000 \$$ were significantly less likely to report FMD compared to adults having an annual income of less than $15,000 \$$. The nonoverlapping confidence intervals indicated statistically significant decline in the odds of FMD with each higher income category; participants having an annual income of 50,000 \$ or more showed the lowest odds of FMD (OR: 0.23, 95\% CI: 0.22-0.25). Participants who were not married at the time of the survey had significantly higher odds of suffering from FMD, compared to those married at the time of the survey. Those who were separated from their partner (OR: 3.40, 95\% CI: 3.10-3.72) had the highest odds followed by the divorced (OR: 2.13, 95\% CI: 2.02-2.25) participants.
Table 3 shows the association of tobacco and alcohol use, dietary practice, physical activity, chronic diseases, and BMI with FMD. Compared to people who were not diagnosed ever with any chronic health condition, individuals who ever had one or more conditions, such as high blood pressure, high cholesterol, heart disease, stroke, asthma, diabetes, and arthritis had higher odds of reporting FMD. The odds of developing FMD were nearly 10 times among people who had been ever diagnosed with all of the chronic conditions, compared to those without any of those conditions. Underweight (unadjusted OR: 1.74, 95\% CI: 1.53, 1.98) and obese (unadjusted OR: 1.62, 95\% CI: 1.54, 1.69) participants had significantly higher odds of having FMD compared with people in the normal range for BMI.

3.3. Multivariable Analysis Results. Excluding the "don't know/not sure," "refused," and missing responses at random 
TABLE 2: Relationship of demographic characteristics with FMD among adults in the United States, BRFSS 2011.

\begin{tabular}{|c|c|c|c|c|c|c|c|}
\hline \multirow{2}{*}{ Variable } & \multirow[b]{2}{*}{ Categories } & \multirow[b]{2}{*}{$\begin{array}{l}\text { Number of } \\
\text { respondents }^{\mathrm{a}}\end{array}$} & \multirow[b]{2}{*}{$\%^{\mathrm{c}}$} & \multicolumn{4}{|c|}{ FMD } \\
\hline & & & & $\begin{array}{l}\text { Number of } \\
\text { respondents }\end{array}$ & $\%^{\mathrm{d}}$ & $\begin{array}{l}\text { Unadjusted } \\
\text { OR }\end{array}$ & $95 \% \mathrm{CI}$ \\
\hline \multirow{6}{*}{ Age category ${ }^{\mathrm{b}}$ (years) } & $18-24$ & 22769 & 12.95 & 2788 & 12.24 & 1 & \\
\hline & $25-34$ & 48997 & 17.74 & 5920 & 12.08 & 1.10 & $1.01-1.21^{*}$ \\
\hline & $35-44$ & 64603 & 17.63 & 7827 & 12.12 & 1.13 & $1.04-1.24^{* *}$ \\
\hline & $45-54$ & 90745 & 18.88 & 12461 & 13.73 & 1.23 & $1.13-1.34^{* * *}$ \\
\hline & $55-64$ & 113460 & 15.43 & 13837 & 12.2 & 1.10 & $1.01-1.19^{*}$ \\
\hline & $\geq 65$ & 156128 & 17.37 & 10882 & 6.97 & 0.61 & $0.56-0.67^{* * *}$ \\
\hline \multirow{2}{*}{ Gender $^{\mathrm{b}}$} & Males & 195315 & 48.76 & 17463 & 8.94 & 1 & \\
\hline & Females & 301387 & 51.24 & 36252 & 12.03 & 1.39 & $1.34-1.44^{* * *}$ \\
\hline \multirow{6}{*}{ Race and ethnicity ${ }^{\mathrm{b}}$} & Non-Hispanic White & 389117 & 66.58 & 39492 & 10.15 & 1 & \\
\hline & Black non-Hispanics & 40073 & 11.18 & 5393 & 13.46 & 1.27 & $1.19-1.35^{* * *}$ \\
\hline & Asian non-Hispanic & 9329 & 3.93 & 500 & 5.36 & 0.50 & $0.42-0.60^{* * *}$ \\
\hline & $\begin{array}{l}\text { American Indian/Alaska Native } \\
\text { non-Hispanic }\end{array}$ & 6899 & 1.07 & 1152 & 16.70 & 1.72 & $1.51-1.96^{* * *}$ \\
\hline & Hispanic & 37839 & 15.08 & 4867 & 12.86 & 1.10 & $1.04-1.17^{* *}$ \\
\hline & Other race non-Hispanic & 13445 & 2.16 & 2311 & 17.19 & 1.72 & $1.54-1.91^{* * *}$ \\
\hline \multirow{4}{*}{ Education $^{\mathrm{b}}$} & Did not graduate from high school & 44407 & 15.09 & 7953 & 17.91 & 1 & \\
\hline & Graduated from high school & 146050 & 29.21 & 18043 & 12.35 & 0.62 & $0.58-0.66^{* * *}$ \\
\hline & $\begin{array}{l}\text { Attended college or technical } \\
\text { school }\end{array}$ & 133821 & 30.12 & 15918 & 11.89 & 0.58 & $0.55-0.62^{* * *}$ \\
\hline & $\begin{array}{l}\text { Graduated from college or } \\
\text { technical school }\end{array}$ & 170627 & 25.59 & 11601 & 6.80 & 0.31 & $0.29-0.33^{* * *}$ \\
\hline \multirow{8}{*}{ Employment status $^{\mathrm{b}}$} & Employed for wages & 204714 & 47.54 & 16393 & 8.01 & 1 & \\
\hline & Self-employed & 39681 & 7.85 & 2958 & 7.45 & 1.01 & $0.93-1.10$ \\
\hline & Out of work for $>1$ year & 16683 & 4.77 & 3771 & 22.60 & 3.20 & $2.94-3.49^{* * *}$ \\
\hline & Out of work for $<1$ year & 13709 & 4.36 & 2611 & 19.05 & 2.66 & $2.41-2.93^{* * *}$ \\
\hline & Homemaker & 34526 & 6.94 & 3333 & 9.65 & 1.31 & $1.21-1.42^{* * *}$ \\
\hline & Student & 11299 & 5.88 & 1393 & 12.33 & 1.32 & $1.18-1.48^{* * *}$ \\
\hline & Retired & 138696 & 16.28 & 9369 & 6.76 & 0.84 & $0.79-0.89^{* * *}$ \\
\hline & Unable to work & 34986 & 6.37 & 13590 & 38.84 & 7.31 & $6.89-7.75^{* * *}$ \\
\hline \multirow{5}{*}{ Annual income (\$) } & $<15000$ & 53554 & 13.51 & 12973 & 24.22 & 1 & \\
\hline & 15000 to less than 25000 & 77697 & 18.67 & 11639 & 14.98 & 0.59 & $0.56-0.63^{* * *}$ \\
\hline & 25000 to less than 35000 & 50913 & 11.47 & 5486 & 10.78 & 0.43 & $0.40-0.47^{* * *}$ \\
\hline & 35000 to less than 50000 & 63685 & 13.92 & 5595 & 8.79 & 0.34 & $0.32-0.36^{* * *}$ \\
\hline & 50000 or more & 180314 & 42.43 & 10863 & 6.02 & 0.23 & $0.22-0.25^{* * *}$ \\
\hline \multirow{6}{*}{ Marital status } & Currently married & 264399 & 50.44 & 21435 & 8.11 & 1 & \\
\hline & Divorced & 69630 & 10.27 & 11431 & 16.42 & 2.13 & $2.02-2.25^{* * *}$ \\
\hline & Widowed & 67348 & 6.83 & 6643 & 9.86 & 1.31 & $1.23-1.40^{* * *}$ \\
\hline & Separated & 10763 & 2.55 & 2699 & 25.08 & 3.40 & $3.10-3.72^{* * *}$ \\
\hline & Never married & 69400 & 24.77 & 9423 & 13.58 & 1.56 & $1.48-1.65^{* * *}$ \\
\hline & A member of an unmarried couple & 12672 & 5.13 & 1784 & 14.08 & 1.65 & $1.49-1.83^{* * *}$ \\
\hline
\end{tabular}

CI: confidence interval; FMD: frequent mental distress; OR: odds ratio. ${ }^{*} P<0.05 ;{ }^{* *} P<0.01 ;{ }^{* * *} P<0.0001$.

${ }^{a}$ The total number of respondents for the variables differs because of unequal number of missing values.

${ }^{b}$ The number of respondents within each category differs from that in Table 1, because all individuals with missing responses for the sociodemographic variable and FMD are excluded.

${ }^{c}$ Weighted percentage of respondents in each category out of the total number of respondents for that characteristic.

${ }^{\mathrm{d}}$ Percentage with FMD among respondents within each category. 
TABLE 3: Relationship of lifestyle factors, chronic disease, and BMI among adults in the United States, BRFSS 2011.

\begin{tabular}{|c|c|c|c|c|c|c|c|}
\hline \multirow[b]{2}{*}{ Variable } & \multirow[b]{2}{*}{ Categories } & \multirow[b]{2}{*}{$\begin{array}{l}\text { Number of } \\
\text { respondents }^{\mathrm{a}}\end{array}$} & \multirow[b]{2}{*}{$\%^{c}$} & \multicolumn{4}{|c|}{ FMD } \\
\hline & & & & $\begin{array}{l}\text { Number of } \\
\text { respondents }\end{array}$ & $\%^{\mathrm{d}}$ & $\begin{array}{l}\text { Unadjusted } \\
\text { OR }\end{array}$ & $95 \% \mathrm{CI}$ \\
\hline \multirow{4}{*}{ Tobacco use } & $\begin{array}{l}\text { Never used tobacco or smoked } \\
<100 \text { cigarettes in life }\end{array}$ & 260343 & 53.82 & 20791 & 7.99 & 1 & \\
\hline & Everyday & 68140 & 15.87 & 14418 & 21.16 & 2.98 & $2.84-3.14^{* * *}$ \\
\hline & Some of the days but not everyday & 25669 & 6.63 & 4382 & 17.07 & 2.26 & $2.09-2.46^{* * *}$ \\
\hline & $\begin{array}{l}\text { Previous user of smokeless tobacco } \\
\text { or smoked }<100 \text { cigarettes in life }\end{array}$ & 140339 & 23.68 & 13896 & 9.90 & 1.27 & $1.21-1.34^{* * *}$ \\
\hline \multirow{4}{*}{ Alcohol use } & $\begin{array}{l}\text { Did not use alcohol at all in the } \\
\text { previous } 30 \text { days }\end{array}$ & 224922 & 45.14 & 27909 & 12.41 & 1 & \\
\hline & $\begin{array}{l}\text { Drank at least once in the past } 30 \\
\text { days but not a heavy or binge } \\
\text { drinker }\end{array}$ & 167928 & 35.24 & 13558 & 8.07 & 0.64 & $0.61-0.67^{* * *}$ \\
\hline & Heavy drinker & 7426 & 1.22 & 668 & 9.00 & 0.73 & $0.62-0.85^{* * *}$ \\
\hline & Binge drinker & 60055 & 18.41 & 7190 & 11.97 & 0.96 & $0.90-1.01$ \\
\hline \multirow{5}{*}{$\begin{array}{l}\text { Dietary practice (daily } \\
\text { intake of fruits, fruit } \\
\text { juice, vegetables, and } \\
\text { beans) }\end{array}$} & None of them & 1051 & 0.25 & 283 & 26.93 & 1 & \\
\hline & One of them & 9824 & 2.13 & 1773 & 18.05 & 0.81 & $0.57-1.15$ \\
\hline & Two of them & 46658 & 9.52 & 6763 & 14.49 & 0.62 & $0.44-0.87^{* *}$ \\
\hline & Three of them & 166057 & 33.18 & 18767 & 11.30 & 0.47 & $0.33-0.65^{* * *}$ \\
\hline & All of them & 254921 & 54.92 & 24041 & 9.43 & 0.38 & $0.27-0.54^{* * *}$ \\
\hline \multirow{5}{*}{$\begin{array}{l}\text { Physical activity in } \\
\text { previous } 30 \text { days }\end{array}$} & $\begin{array}{l}\text { No physical activity or exercise } \\
\text { other than regular work }\end{array}$ & 126867 & 25.52 & 20240 & 15.95 & 1 & \\
\hline & $\begin{array}{l}\text { Met aerobic and strengthening } \\
\text { guidelines }\end{array}$ & 85231 & 19.72 & 6084 & 7.14 & 0.44 & $0.41-0.47^{* * *}$ \\
\hline & Met aerobic guidelines & 151670 & 29.72 & 13009 & 8.58 & 0.53 & $0.50-0.55^{* * *}$ \\
\hline & Met strengthening guidelines & 22798 & 6.12 & 2046 & 8.97 & 0.51 & $0.46-0.57^{* * *}$ \\
\hline & $\begin{array}{l}\text { Met neither guideline but had } \\
\text { physical activity }\end{array}$ & 87991 & 18.92 & 9759 & 11.09 & 0.67 & $0.64-0.71^{* * *}$ \\
\hline \multirow{8}{*}{$\begin{array}{l}\text { Number of chronic } \\
\text { diseases ever diagnosed } \\
\text { d }\end{array}$} & None of them & 157422 & 38.28 & 11082 & 7.04 & 1 & \\
\hline & One & 130048 & 23.06 & 12432 & 9.56 & 1.52 & $1.44-1.61^{* * *}$ \\
\hline & Two & 99824 & 13.90 & 11503 & 11.52 & 1.90 & $1.79-2.02^{* * *}$ \\
\hline & Three & 65288 & 8.04 & 9381 & 14.37 & 2.38 & $2.23-2.54^{* * *}$ \\
\hline & Four & 30769 & 3.43 & 5831 & 18.95 & 3.22 & $2.99-3.47^{* * *}$ \\
\hline & Five & 10536 & 1.10 & 2599 & 24.67 & 4.26 & $3.85-4.72^{* * *}$ \\
\hline & Six & 2447 & 0.22 & 751 & 30.69 & 5.86 & $4.93-6.98^{* * *}$ \\
\hline & Seven & 368 & 0.03 & 136 & 36.96 & 9.76 & $6.53-14.61^{* * *}$ \\
\hline \multirow{4}{*}{ BMI category ${ }^{b}$} & Normal & 160465 & 34.88 & 14812 & 9.23 & 1 & \\
\hline & Underweight & 8043 & 1.86 & 1235 & 15.35 & 1.74 & $1.53-1.98^{* * *}$ \\
\hline & Overweight & 170601 & 35.85 & 15934 & 9.34 & 1.02 & $0.97-1.07$ \\
\hline & Obese & 130700 & 27.41 & 18846 & 14.42 & 1.62 & $1.54-1.69^{* * *}$ \\
\hline
\end{tabular}

BMI: body mass index; CI: confidence interval; FMD: frequent mental distress; OR: odds ratio.

${ }^{*} P<0.05 ;{ }^{* *} P<0.01 ;{ }^{* * *} P<0.0001$.

${ }^{a}$ The total number of respondents for the variables differs because of unequal number of missing values.

${ }^{b}$ The number of respondents within each category differs from that in Table 1, because all individuals with missing responses for BMI and FMD are excluded.

${ }^{c}$ Weighted percentage of respondents in each category out of the total number of respondents for that characteristic.

${ }^{\mathrm{d}}$ Percentage with FMD among respondents within each category.

for all of the variables, a total of 380,637 participants were included in multivariable analysis. Underweight (AOR: 1.34, 95\% CI: $1.13,1.60$ ) and obese (AOR: $1.13,95 \%$ CI: $1.06,1.20$ ) participants were significantly more likely to report FMD (Table 4). Females had significantly higher odds of reporting
FMD compared to males (AOR: 1.54 ; 95\% CI: 1.46, 1.62). NonHispanic Blacks, non-Hispanic Asians, and Hispanics were less likely than non-Hispanic Whites to have FMD. Current or lifetime tobacco users (those who have smoked at least 100 cigarettes in their entire life) and binge drinkers were 
TABLE 4: Adjusted odds ratios ${ }^{\mathrm{a}}$ of having FMD among adults in the United States, BRFSS $2011(N=380637)$.

\begin{tabular}{|c|c|c|c|}
\hline Variable $^{b}$ & Categories & Adjusted OR & 95\% CI \\
\hline \multirow{5}{*}{ Age in years (ref: 18-24) } & $25-34$ & 1.07 & $0.96-1.20$ \\
\hline & $35-44$ & 1.04 & $0.93-1.17$ \\
\hline & $45-54$ & 0.86 & $0.77-0.97^{*}$ \\
\hline & $55-64$ & 0.60 & $0.53-0.68^{* * *}$ \\
\hline & $\geq 65$ & 0.33 & $0.29-0.38^{* * *}$ \\
\hline Gender (ref: male) & Females & 1.54 & $1.46-1.62^{* * *}$ \\
\hline \multirow{5}{*}{ Race and ethnicity (ref: non-Hispanic White) } & Black non-Hispanics & 0.84 & $0.78-0.92^{* * *}$ \\
\hline & Asian non-Hispanic & 0.74 & $0.59-0.92^{* *}$ \\
\hline & American Indian/Alaska Native non-Hispanic & 1.07 & $0.90-1.27$ \\
\hline & Hispanic & 0.91 & $0.84-0.98^{*}$ \\
\hline & Other race non-Hispanic & 1.26 & $1.11-1.43^{* *}$ \\
\hline \multirow{3}{*}{$\begin{array}{l}\text { Education (ref: did not graduate from high } \\
\text { school) }\end{array}$} & Graduated from high school & 0.86 & $0.80-0.93^{* *}$ \\
\hline & Attended college or technical school & 0.95 & $0.87-1.03$ \\
\hline & Graduated from college or technical school & 0.79 & $0.72-0.87^{* * *}$ \\
\hline \multirow{7}{*}{ Employment status (ref: employed for wages) } & Self-employed & 1.10 & $1.00-1.21^{*}$ \\
\hline & Out of work for $>1$ year & 2.14 & $1.93-2.37^{* * *}$ \\
\hline & Out of work for $<1$ year & 1.99 & $1.77-2.23^{* * *}$ \\
\hline & Homemaker & 1.17 & $1.06-1.28^{* *}$ \\
\hline & Student & 1.31 & $1.14-1.51^{* *}$ \\
\hline & Retired & 1.18 & $1.08-1.29^{* *}$ \\
\hline & Unable to work & 3.43 & $3.16-3.73^{* * *}$ \\
\hline \multirow{4}{*}{ Annual income in $\$($ ref: $<15000)$} & 15000 to less than 25000 & 0.77 & $0.72-0.83^{* * *}$ \\
\hline & 25000 to less than 35000 & 0.72 & $0.66-0.79^{* * *}$ \\
\hline & 35000 to less than 50000 & 0.63 & $0.57-0.69^{* * *}$ \\
\hline & 50000 or more & 0.53 & $0.48-0.58^{* * *}$ \\
\hline \multirow{5}{*}{ Marital status (ref: currently married) } & Divorced & 1.19 & $1.12-1.27^{* * *}$ \\
\hline & Widowed & 1.06 & $0.97-1.16$ \\
\hline & Separated & 1.60 & $1.43-1.79^{* * *}$ \\
\hline & Never married & 1.12 & $1.04-1.21^{* *}$ \\
\hline & A member of an unmarried couple & 1.16 & $1.02-1.31^{*}$ \\
\hline \multirow{3}{*}{$\begin{array}{l}\text { Tobacco use (ref: never used tobacco or } \\
\text { smoked }<100 \text { cigarettes in life) }\end{array}$} & Everyday & 1.92 & $1.80-2.04^{* * *}$ \\
\hline & Some of the days but not everyday & 1.70 & $1.54-1.87^{* * *}$ \\
\hline & $\begin{array}{l}\text { Previous user of smokeless tobacco or smoked } \\
<100 \text { cigarettes in life }\end{array}$ & 1.22 & $1.15-1.29^{* * *}$ \\
\hline \multirow{3}{*}{$\begin{array}{l}\text { Alcohol use (ref: did not use alcohol at all in } \\
\text { the previous } 30 \text { days) }\end{array}$} & $\begin{array}{l}\text { Drank at least once in the past } 30 \text { days but not } \\
\text { a heavy or binge drinker }\end{array}$ & 0.98 & $0.92-1.03$ \\
\hline & Heavy drinker & 1.08 & $0.89-1.31$ \\
\hline & Binge drinker & 1.17 & $1.09-1.25^{* * *}$ \\
\hline Dietary practice $^{c}$ & & 0.92 & $0.90-0.95^{* * *}$ \\
\hline \multirow{4}{*}{$\begin{array}{l}\text { Physical activity in previous } 30 \text { days (ref: no } \\
\text { physical activity or exercise other than regular } \\
\text { work) }\end{array}$} & Met aerobic and strengthening guidelines & 0.68 & $0.63-0.73^{* * *}$ \\
\hline & Met aerobic guidelines & 0.71 & $0.67-0.76^{* * *}$ \\
\hline & Met strengthening guidelines & 0.78 & $0.70-0.88^{* * *}$ \\
\hline & Met neither guideline but had physical activity & 0.81 & $0.76-0.86^{* * *}$ \\
\hline Number of chronic conditions ever diagnosed ${ }^{c}$ & & 1.33 & $1.31-1.36^{* * *}$ \\
\hline \multirow{3}{*}{ BMI category (ref: normal) } & Underweight & 1.34 & $1.13-1.60^{* *}$ \\
\hline & Overweight & 1.03 & $0.97-1.10$ \\
\hline & Obese & 1.13 & $1.06-1.20^{* * *}$ \\
\hline
\end{tabular}

BMI: body mass index; CI: confidence interval; FMD: frequent mental distress; OR: odds ratio.

${ }^{*} P<0.05 ;{ }^{* *} P<0.01 ;{ }^{* * *} P<0.0001$.

${ }^{\mathrm{a}} \mathrm{OR}$ for each variable is adjusted for all other covariates.

${ }^{\mathrm{b}}$ The reference category for each variable is specified within parenthesis.

${ }^{\mathrm{c}}$ Introduced in the multivariable model as continuous variable. 
more likely to report FMD. Respondents involved in any kind of physical activity outside regular work were significantly less likely to suffer from mental distress. In comparison with participants who were employed for wages, others had higher adjusted odds of reporting FMD. Contrary to bivariate analysis results, retired persons had significantly higher odds of having FMD in multivariable analysis. The significantly reduced odds of FMD with increasing income also persisted even after controlling for all covariates. Divorced, separated, and never married people had higher adjusted odds of suffering from FMD, compared to those married when the survey took place. With each additional ever-diagnosed chronic health condition, there was a $33 \%$ increase in the odds of having FMD.

3.4. Association of FMD with BMI Separately in Males and Females. As presented in Table 5, being out of work and being unable to work were significantly associated with FMD for both sexes. Divorced and separated males as well as females had higher odds of reporting FMD. Unlike women, widowed men had higher odds (AOR: 1.61, 95\% CI: 1.35-1.93) of suffering from FMD compared to men who were married at the time of the survey. Higher income was associated with decreased odds of FMD for both genders.

The overlapping confidence intervals indicate that adjusted ORs of having FMD were not significantly different between males and females for any of the categories of BMI (Table 5). Females, who were underweight (AOR: 1.33, 95\% CI: 1.10, 1.60), overweight (AOR: 1.10, 95\% CI: 1.03, 1.19), and obese (AOR: 1.21, 95\% CI: 1.13, 1.31), had statistically significant higher odds of reporting FMD compared to females with normal BMI. For males, adjusted ORs of reporting FMD among underweight (AOR: 1.40, 95\% CI: 0.98, 1.99), overweight (AOR: 0.97, 95\% CI: 0.88-1.07), and obese (AOR: 1.05, 95\% CI: 0.95-1.17) did not significantly differ from males with normal BMI.

\section{Discussion}

4.1. Prevalence and Distribution of FMD. From this analysis, the prevalence of FMD (unweighted: $10.8 \%$, weighted: $12 \%$ ) among U.S. adults in 2011 was similar to that reported in the previous years $[29,46,47]$. The finding that females have a significantly higher risk of FMDs has also been consistent over the years [29]. Similar to previous findings [28, 29] people of all racial and ethnic backgrounds other than Asians were more likely to have FMD compared with non-Hispanic Whites. Interestingly, when all the other factors were controlled for, non-Hispanic Blacks and Hispanics were less likely to report FMD than Whites. In some earlier studies, Blacks and Hispanics were less likely to have depression and anxiety than Whites [48].

4.2. FMD and BMI in Males and Females Combined. From Table 4, people who were underweight and obese had higher adjusted odds of FMD compared to people with normal BMI. An analysis of data from the third (1988-1994) National Health and Nutrition Examination Survey (NHANES) found that severe obesity (BMI $\geq 40)$ was associated with depression
[49]. Findings from the HUNT study [15] suggest an increase in the risk of depression with increase in BMI. However, the HUNT study was a prospective study, which evaluated an entirely different population, a county in Norway [15].

Unlike a previous finding [37], underweight people in this study had higher odds of FMD compared to those with normal BMI, even after adjusting for confounders, such as smoking, being unmarried, or unemployed [39-41]. The findings follow a pattern with people in both the lower and higher ranges of BMI having poorer mental health [50]. Certain specific mental problems (e.g., anxiety disorders) are often more common among underweight men [51].

In this analysis, consumption of fruits/fruit juice, vegetables, and beans decreased the risk of having FMD. This might be because healthy food items, such as fruits and vegetables, have a potential role in the prevention of mental health disorders [27]. Underweight people often suffer from malnutrition [52] and micronutrient deficiency, which are biological risk factors for poor mental health [53-55]. On the other hand, mental health problems, such as mood disorders and anorexia, may influence BMI $[56,57]$.

Tobacco use and lack of physical activity were significantly associated with FMD, similar to what is usually observed $[9,10]$. The association of binge drinking with FMD in the present study corroborates with previous findings [58]. Similar to the findings by Zhao et al. $[28,50]$, being diagnosed with a chronic disease ever was associated with significantly higher odds of mental distress.

4.3. Gender-Specific Analysis of the Association between FMD and BMI. Gender-specific analysis showed that the adjusted ORs were not significantly different between the sexes, for any of the BMI categories. However, among women who were underweight, overweight, or obese, the odds of having FMD were significantly higher compared to women with normal BMI. Results of a previous study [49] are comparable to some extent, but it did not find any relationship between underweight and mental distress [49]. A 2005 report mentioned that a women-specific association may exist between obesity and depression [17]. Gender differences were not observed in all studies [28]. Anxiety and depression had a significantly higher prevalence among underweight, overweight, or obese women as well as underweight men in an analysis of 2006 BRFSS data [50]. In the Hunt Study [15] higher, but not lower, BMI was associated with an increased risk of depression at follow-up in both men and women.

Obese women tend to internalize the ridicule and stigma experienced in public and from their own family members [21, 59], which might explain their mental distress. A distorted body image $[22,23]$, underlying anorexia nervosa, and dieting to lose weight [25] could influence the association between less than adequate BMI and poor mental health [23].

4.4. Limitations. This study has several limitations. All the variables were self-reported by the respondents and could be subject to recall bias. People may tend to underreport mental distress due to social-acceptability bias. Besides, the benchmark for having "good" or "not good" mental health can vary from person to person. Quality of sleep and its duration 
TABLE 5: Adjusted odds ratios ${ }^{\mathrm{a}}$ of having FMD among adults in the United States, stratified by gender, BRFSS 2011.

\begin{tabular}{|c|c|c|c|c|c|}
\hline \multirow{2}{*}{ Variable $^{b}$} & \multirow{2}{*}{ Categories } & \multicolumn{2}{|c|}{ Females $(N=221623)$} & \multicolumn{2}{|c|}{ Males $(N=159014)$} \\
\hline & & Adjusted OR & $95 \% \mathrm{CI}$ & Adjusted OR & $95 \% \mathrm{CI}$ \\
\hline \multirow{5}{*}{$\begin{array}{l}\text { Age category (years) (ref: } \\
18-24)\end{array}$} & $25-34$ & 1.06 & $0.91-1.23$ & 1.11 & $0.94-1.31$ \\
\hline & $35-44$ & 1.04 & $0.89-1.21$ & 1.06 & $0.89-1.26$ \\
\hline & $45-54$ & 0.88 & $0.76-1.03$ & 0.83 & $0.70-0.99^{*}$ \\
\hline & $55-64$ & 0.61 & $0.52-0.71^{* * *}$ & 0.60 & $0.50-0.73^{* * *}$ \\
\hline & $\geq 65$ & 0.34 & $0.28-0.40^{* * *}$ & 0.34 & $0.27-0.42^{* * *}$ \\
\hline \multirow{5}{*}{$\begin{array}{l}\text { Race and ethnicity (ref: } \\
\text { non-Hispanic White) }\end{array}$} & Black non-Hispanic & 0.81 & $0.73-0.89^{* * *}$ & 0.88 & $0.77-1.01$ \\
\hline & Asian non-Hispanic & 0.77 & $0.57-1.04$ & 0.72 & $0.53-0.99^{*}$ \\
\hline & $\begin{array}{l}\text { American Indian/Alaska Native } \\
\text { non-Hispanic }\end{array}$ & 0.93 & $0.75-1.15$ & 1.20 & $0.91-1.57$ \\
\hline & Hispanic & 0.90 & $0.81-0.99^{*}$ & 0.92 & $0.81-1.04$ \\
\hline & Other race non-Hispanic & 1.15 & $0.97-1.35$ & 1.38 & $1.13-1.68^{* *}$ \\
\hline \multirow{3}{*}{$\begin{array}{l}\text { Education (ref: did not } \\
\text { graduate from high school) }\end{array}$} & Graduated from high school & 0.89 & $0.81-0.99^{*}$ & 0.84 & $0.74-0.95^{* *}$ \\
\hline & Attended college or technical school & 0.99 & $0.89-1.10$ & 0.90 & $0.79-1.03$ \\
\hline & Graduated from college or technical school & 0.82 & $0.73-0.92^{* *}$ & 0.75 & $0.65-0.87^{* * *}$ \\
\hline \multirow{7}{*}{$\begin{array}{l}\text { Employment status (ref: } \\
\text { employed for wages) }\end{array}$} & Self-employed & 1.10 & $0.96-1.24$ & 1.14 & $1.00-1.29$ \\
\hline & Out of work for $>1$ year & 1.95 & $1.72-2.21^{* * *}$ & 2.36 & $2.01-2.78^{* * *}$ \\
\hline & Out of work for $<1$ year & 1.83 & $1.57-2.12^{* * *}$ & 2.15 & $1.82-2.56^{* * *}$ \\
\hline & Homemaker & 1.10 & $1.00-1.22^{*}$ & - & \\
\hline & Student & 1.41 & $1.18-1.67^{* * *}$ & 1.14 & $0.88-1.46$ \\
\hline & Retired & 1.03 & $0.94-1.14$ & 1.33 & $1.14-1.56^{* *}$ \\
\hline & Unable to work & 3.23 & $2.92-3.57^{* * *}$ & 3.66 & $3.19-4.20^{* * *}$ \\
\hline \multirow{4}{*}{$\begin{array}{l}\text { Annual income (\$) (ref: } \\
<15000)\end{array}$} & 15000 to less than 25000 & 0.75 & $0.69-0.82^{* * *}$ & 0.80 & $0.71-0.90^{* *}$ \\
\hline & 25000 to less than 35000 & 0.71 & $0.63-0.79^{* * *}$ & 0.74 & $0.64-0.86^{* * *}$ \\
\hline & 35000 to less than 50000 & 0.59 & $0.53-0.66^{* * *}$ & 0.67 & $0.58-0.78^{* * *}$ \\
\hline & 50000 or more & 0.53 & $0.48-0.60^{* * *}$ & 0.53 & $0.46-0.61^{* * *}$ \\
\hline \multirow{5}{*}{$\begin{array}{l}\text { Marital status (ref: } \\
\text { currently married) }\end{array}$} & Divorced & 1.16 & $1.08-1.26^{* *}$ & 1.23 & $1.11-1.37^{* *}$ \\
\hline & Widowed & 0.95 & $0.86-1.05$ & 1.61 & $1.35-1.93^{* * *}$ \\
\hline & Separated & 1.58 & $1.38-1.82^{* * *}$ & 1.61 & $1.33-1.95^{* * *}$ \\
\hline & Never married & 1.11 & $1.00-1.22^{*}$ & 1.13 & $1.01-1.26^{*}$ \\
\hline & A member of an unmarried couple & 1.18 & $1.02-1.37^{*}$ & 1.13 & $0.92-1.38$ \\
\hline \multirow{3}{*}{$\begin{array}{l}\text { Tobacco use (ref: never } \\
\text { used tobacco or smoked } \\
<100 \text { cigarettes in life) }\end{array}$} & Everyday & 2.02 & $1.87-2.18^{* * *}$ & 1.77 & $1.60-1.97^{* * *}$ \\
\hline & Some of the days but not everyday & 1.71 & $1.52-1.92^{* * *}$ & 1.66 & $1.43-1.93^{* * *}$ \\
\hline & $\begin{array}{l}\text { Previous user of smokeless tobacco or } \\
\text { smoked }<100 \text { cigarettes in life }\end{array}$ & 1.20 & $1.12-1.29^{* * *}$ & 1.20 & $1.08-1.32^{* *}$ \\
\hline \multirow{3}{*}{$\begin{array}{l}\text { Alcohol use (ref: not used } \\
\text { alcohol at all in the } \\
\text { previous } 30 \text { days) }\end{array}$} & $\begin{array}{l}\text { Drank at least once in the past } 30 \text { days but } \\
\text { not a heavy or binge drinker }\end{array}$ & 1.05 & $0.98-1.12$ & 0.88 & $0.80-0.96^{* *}$ \\
\hline & Heavy drinker & 1.09 & $0.88-1.34$ & 1.06 & $0.70-1.61$ \\
\hline & Binge drinker & 1.27 & $1.16-1.40^{* * *}$ & 1.08 & $0.98-1.19$ \\
\hline Dietary practice $^{c}$ & & 0.94 & $0.90-0.98^{* *}$ & 0.91 & $0.87-0.96^{* *}$ \\
\hline \multirow{4}{*}{$\begin{array}{l}\text { Physical activity in previous } \\
30 \text { days (ref: no physical } \\
\text { activity or exercise other } \\
\text { than regular work) }\end{array}$} & Met aerobic and strengthening guidelines & 0.65 & $0.59-0.72^{* * *}$ & 0.71 & $0.63-0.80^{* * *}$ \\
\hline & Met aerobic guidelines & 0.68 & $0.63-0.73^{* * *}$ & 0.75 & $0.68-0.83^{* * *}$ \\
\hline & Met strengthening guidelines & 0.72 & $0.62-0.83^{* * *}$ & 0.86 & $0.72-1.02$ \\
\hline & $\begin{array}{l}\text { Met neither guideline but had physical } \\
\text { activity }\end{array}$ & 0.78 & $0.72-0.84^{* * *}$ & 0.85 & $0.75-0.95^{* *}$ \\
\hline $\begin{array}{l}\text { Number of chronic } \\
\text { conditions ever diagnosed }^{\mathrm{c}}\end{array}$ & & 1.34 & $1.31-1.37^{* * *}$ & 1.33 & $1.29-1.38^{* * *}$ \\
\hline \multirow{3}{*}{ BMI category (ref: normal) } & Underweight & 1.33 & $1.10-1.60^{* *}$ & 1.40 & $0.98-1.99$ \\
\hline & Overweight & 1.10 & $1.03-1.19^{* *}$ & 0.97 & $0.88-1.07$ \\
\hline & Obese & 1.21 & $1.13-1.31^{* * *}$ & 1.05 & 0.95-1.17 \\
\hline
\end{tabular}

BMI: body mass index; CI: confidence interval; FMD: frequent mental distress; OR: odds ratio.

${ }^{*} P<0.05 ;{ }^{* *} P<0.01 ;{ }^{* * *} P<0.0001$.

${ }^{a}$ OR for each variable is adjusted for all other covariates.

${ }^{\mathrm{b}}$ The reference category for each variable is specified within parenthesis.

${ }^{\mathrm{c}}$ Introduced in the multivariable model as continuous variable. 
can affect both BMI [60] and mental health. Unfortunately, sleep related variables could not be included in this analysis, because of very few valid responses. Another potential confounder not taken into account is the intake of certain psychiatric medications, which can lead to weight gain [61]. The way in which some of the variables were combined for operational purposes (e.g., diet) was arbitrary and might not have been the best way to do so. For most of the questions, there were respondents who refused to answer or responded as "don't know/not sure." These people, excluded from analysis, could be different in their behaviors, resulting in self-selection bias. However, a comparison of the characteristics of the sample between Tables 1 and 2 indicates that the percentages are fairly similar. Another drawback was that, after excluding all the missing values for all the variables, the sample size decreased considerably compared to bivariate analysis. This might partially be responsible for the differences in odds ratios between bivariate and multivariable analysis results. BMI is not always the most reliable indicator of body fat, and factors like the individual's waist circumference were not included in the survey $[62,63]$. Mental health problems such as depression and anxiety, are not uncommon during pregnancy and it would be nice to look at the relationship of prepregnancy $\mathrm{BMI}$, gestational gain in body weight, and mental distress among pregnant women $[64,65]$. This was a cross-sectional survey; hence causality cannot be inferred. Also, there was no opportunity to evaluate the association of individual mental health disorders separately with the independent variables. Chronic health conditions have been grouped together, but some specific disorders, such as diabetes, are found to be associated with mental disorders, such as depression [66].

\section{Conclusions}

This study has used data from a very recent nationally representative sample. FMD, an indicator of Health-Related Quality of Life, indicates the assessment of a person about his or her own mental well-being [47]. A lot of confounding factors have been taken into account. The findings suggest that there could be a relationship between BMI and FMD independent of sociodemographic characteristics, risk-behaviors, lifestyle factors, and chronic diseases. Future research should explore longitudinal trend, whether abnormal BMI from an early age precedes mental distress, or vice versa. Measuring stigma and discrimination experienced by an overweight, obese, or underweight individual would be vital in understanding their role as potential mediators.

\section{Conflict of Interests}

The author declares that there was no conflict of interests in the preparation and writing of this paper.

\section{Acknowledgment}

The author received no funding for this study. He is a recipient of the Presidential Fellowship Award from Florida International University, 2011-2014.

\section{References}

[1] United States Department of Health and Human Services, "Mental health: A report of the surgeon general," Rockville, Md, USA, U.S. Department of Health and Human Services, Substance Abuse and Mental Health Services Administration, Center for Mental Health Services, National Institutes of Health, National Institute of Mental Health, 1999.

[2] Fact sheet CDC report: Mental illness surveillance among adults in the united states, CDC, http://www.cdc.gov/mentalhealthsurveillance/fact_sheet.html.

[3] R. C. Kessler, W. T. Chiu, L. Colpe et al., "The prevalence and correlates of serious mental illness (SMI) in the national comorbidity survey replication (NCS-R)," in Mental Health, United States 2004, R. W. Manderscheid and J. T. Berry, Eds., pp. 134-148, Substance Abuse and Mental Health Services Administration, Rockville, Md, USA, 2004.

[4] Burden of mental illness, 2011, http://www.cdc.gov/mentalhealth/basics/burden.htm.

[5] Centers for Disease Control \& Prevention, "Self-reported frequent mental distress among adults- united states, 1993-2001," Morbidity and Mortality Weekly Report, vol. 53, pp. 963-966, 2004.

[6] T. W. Strine, A. H. Mokdad, L. S. Balluz, J. T. Berry, and O. Gonzalez, "Impact of depression and anxiety on quality of life, health behaviors, and asthma control among adults in the United States with asthma, 2006," Journal of Asthma, vol. 45, no. 2, pp. 123-133, 2008.

[7] E. Hall and E. J. Johnson, Suicide and Suicidal Thoughts By Oregonians, Oregon Center for Health Statistics, Portland, Ore, USA, 1997.

[8] D. P. Chapman, G. S. Perry, and T. W. Strine, "The vital link between chronic disease and depressive disorders," Preventing Chronic Disease, vol. 2, no. 1, p. A14, 2005.

[9] L. Bensley, J. Van Eenwyk, and K. W. Simmons, "Childhood family violence history and women's risk for intimate partner violence and poor health," American Journal of Preventive Medicine, vol. 25, no. 1, pp. 38-44, 2003.

[10] P. M. Lewinsohn, P. Rohde, and J. R. Seeley, "Psychosocial risk factors for future adolescent suicide attempts," Journal of Consulting and Clinical Psychology, vol. 62, no. 2, pp. 297-305, 1994.

[11] A. C. Tsai, S. Chi, and J. Wang, "Cross-sectional and longitudinal associations of lifestyle factors with depressive symptoms in $\geq 53$-year old taiwanese-results of an 8-year cohort study," Preventive Medicine, vol. 57, no. 2, pp. 92-97, 2013.

[12] J. E. Rohrer, J. Rush Pierce Jr., and C. Blackburn, "Lifestyle and mental health," Preventive Medicine, vol. 40, no. 4, pp. 438-443, 2005.

[13] A. Pan, Q. Sun, S. Czernichow et al., "Bidirectional association between depression and obesity in middle-aged and older women," International Journal of Obesity, vol. 36, no. 4, pp. 595$602,2012$.

[14] M. J. Huisingh-Scheetz, S. P. Bilir, P. Rush, D. Burnet, and W. Dale, "The independent effect of body mass index on healthrelated quality of life among racial and ethnic subgroups," Quality of Life Research, vol. 22, no. 7, pp. 1565-1575, 2012.

[15] A. C. Rivenes, S. B. Harvey, and A. Mykletun, “The relationship between abdominal fat, obesity, and common mental disorders: results from the HUNT Study," Journal of Psychosomatic Research, vol. 66, no. 4, pp. 269-275, 2009.

[16] About BMI for adults, CDC, 2011, http://www.cdc.gov/healthyweight/assessing/bmi/adult_bmi/index.html. 
[17] D. B. Allison, J. W. Newcomer, A. L. Dunn et al., "Obesity among those with mental disorders. A National Institute of Mental Health Meeting Report," American Journal of Preventive Medicine, vol. 36, no. 4, pp. 341-350, 2009.

[18] M. Kivimäki, M. Jokela, M. Hamer et al., "Examining overweight and obesity as risk Factors for Common Mental Disorders Using Fat Mass and Obesity-Associated (FTO) GenotypeInstrumented Analysis," American Journal of Epidemiology, vol. 173, no. 4, pp. 421-429, 2011.

[19] A. L. Lopresti and P. D. Drummond, "Obesity and psychiatric disorders: commonalities in dysregulated biological pathways and their implications for treatment," Progress in NeuroPsychopharmacology \& Biological Psychiatry, vol. 45, pp. 92-99, 2013.

[20] R. Puhl and K. D. Brownell, "Bias, discrimination, and obesity," Obesity Research, vol. 9, no. 12, pp. 788-805, 2001.

[21] D. Carr and M. A. Friedman, "Is obesity stigmatizing? Body weight, perceived discrimination, and psychological well-being in the United States," Journal of Health and Social Behavior, vol. 46, no. 3, pp. 244-259, 2005.

[22] D. M. Garner, “The body image survey results," Psychology Today, vol. 30, pp. 75-84, 1997.

[23] K. E. Friedman, S. K. Reichmann, P. R. Costanzo, and G. J. Musante, "Body image partially mediates the relationship between obesity and psychological distress," Obesity Research, vol. 10, no. 1, pp. 33-41, 2002.

[24] S. Yaemsiri, M. M. Slining, and S. K. Agarwal, "Perceived weight status, overweight diagnosis, and weight control among US adults: the NHANES 2003-2008 Study," International Journal of Obesity, vol. 35, no. 8, pp. 1063-1070, 2011.

[25] J. Stevens, S. K. Kumanyika, and J. E. Keil, "Attitudes toward body size and dieting: Differences between elderly black and white women," American Journal of Public Health, vol. 84, no. 8, pp. 1322-1325, 1994.

[26] S. Brandheim, U. Rantakeisu, and B. Starrin, "BMI and psychological distress in 68,000 swedish adults: a weak association when controlling for an age-gender combination," BMC Public Health, vol. 13, no. 1, article 68, 2013.

[27] S. E. McMartin, F. N. Jacka, and I. Colman, "The association between fruit and vegetable consumption and mental health disorders: evidence from five waves of a national survey of canadians," Preventive Medicine, vol. 56, no. 3-4, pp. 225-230, 2013.

[28] G. Zhao, E. S. Ford, C. Li et al., "Serious psychological distress and its associations with body mass index: findings from the 2007 Behavioral Risk Factor Surveillance System," International Journal of Public Health, vol. 54, supplement, pp. 30-36, 2009.

[29] Health-related quality of life BRFSS trend data, 2012, http://apps .nccd.cdc.gov/HRQOL/.

[30] Non-specific psychological distress, "Surveillance data sources," 2011, http://www.cdc.gov/mentalhealth/data_stats/nspd.htm.

[31] D. W. Black, R. B. Goldstein, and E. E. Mason, "Prevalence of mental disorder in 88 morbidly obese bariatric clinic patients," American Journal of Psychiatry, vol. 149, no. 2, pp. 227-234, 1992.

[32] M. L. Fitzgibbon, M. R. Stolley, and D. S. Kirschenbaum, "Obese people who seek treatment have different characteristics than those who do not seek treatment," Health Psychology, vol. 12, no. 5, pp. 346-353, 1993.

[33] C. F. Telch and W. S. Agras, "Obesity, binge eating and psychopathology: are they related?" International Journal of Eating Disorders, vol. 15, no. 1, pp. 53-61, 1994.
[34] K. M. Scott, R. Bruffaerts, G. E. Simon et al., "Obesity and mental disorders in the general population: results from the world mental health surveys," International Journal of Obesity, vol. 32, no. 1, pp. 192-200, 2008.

[35] I. Hach, U. E. Ruhl, M. Klose, J. Klotsche, W. Kirch, and F. Jacobi, "Obesity and the risk for mental disorders in a representative German adult sample," European Journal of Public Health, vol. 17, no. 3, pp. 297-305, 2007.

[36] S. L. Pagoto, Y. Ma, J. S. Bodenlos et al., "Association of depressive symptoms and lifestyle behaviors among latinos at risk of type 2 diabetes," Journal of the American Dietetic Association, vol. 109, no. 7, pp. 1246-1250, 2009.

[37] S. J. Kelly, J. M. Lilley, and J. Leonardi-Bee, "Associations of morbidity in the underweight," European Journal of Clinical Nutrition, vol. 64, no. 5, pp. 475-482, 2010.

[38] S. J. Kelly, M. Daniel, E. Dal Grande, and A. Taylor, "Mental illhealth across the continuum of body mass index," BMC Public Health, vol. 11, article 765, 2011.

[39] S. M. Ali and M. Lindström, "Socioeconomic, psychosocial, behavioural, and psychological determinants of BMI among young women: differing patterns for underweight and overweight/obesity," European Journal of Public Health, vol. 16, no. 3, pp. 324-330, 2006.

[40] E. J. Groessl, R. M. Kaplan, E. Barrett-Connor, and T. G. Ganiats, "Body mass index and quality of well-being in a community of older adults," American Journal of Preventive Medicine, vol. 26, no. 2, pp. 126-129, 2004.

[41] K. Neovius, K. Johansson, S. Rössner, and M. Neovius, "Disability pension, employment and obesity status: a systematic review," Obesity Reviews, vol. 9, no. 6, pp. 572-581, 2008.

[42] BRFSS today: Facts and highlights, 2013, http://www.cdc.gov/ brfss/about/brfss_today.htm.

[43] 2011 behavioral risk factor surveillance system questionnaire, http://www.cdc.gov/brfss/annual_data/pdf-ques/2011brfss.pdf.

[44] Centers for Disease Control and Prevention (CDC), "Methodologic changes in the behavioral risk factor surveillance system in 2011 and potential effects on prevalence estimates," Morbidity and Mortality Weekly Report, vol. 61, no. 22, pp. 410-413.

[45] Using SAS survey procs for BRFSS descriptive analyses, 30th Annual BRFSS Conference, Atlanta, Ga, USA, 2013, http://www .brfss2013.com/index.php/documents/document/1-using-sassurvey-procs-for-brfss-descriptive-analyses-brogan-3232013?limit $=20 \&$ start $=40$.

[46] D. G. Moriarty, M. M. Zack, J. B. Holt, D. P. Chapman, and M. A. Safran, "Geographic Patterns of Frequent Mental Distress. U.S. Adults, 1993-2001 and 2003-2006," American Journal of Preventive Medicine, vol. 36, no. 6, pp. 497-505, 2009.

[47] E. S. Ford, D. G. Moriarty, M. M. Zack, A. H. Mokdad, and D. P. Chapman, "Self-reported body mass index and health-related quality of life: findings from the Behavioral Risk Factor Surveillance System," Obesity Research, vol. 9, no. 1, pp. 21-31, 2001.

[48] D. M. Barnes, K. M. Keyes, and L. M. Bates, "Racial differences in depression in the United States: how do subgroup analyses inform a paradox?" Social Psychiatry and Psychiatric Epidemiology, pp. 1-9, 2013.

[49] C. U. Onyike, R. M. Crum, H. B. Lee, C. G. Lyketsos, and W. W. Eaton, "Is obesity associated with major depression? Results from the third national health and nutrition examination survey," American Journal of Epidemiology, vol. 158, no. 12, pp. 1139-1147, 2003. 
[50] G. Zhao, E. S. Ford, S. Dhingra, C. Li, T. W. Strine, and A. H. Mokdad, "Depression and anxiety among US adults: associations with body mass index," International Journal of Obesity, vol. 33, no. 2, pp. 257-266, 2009.

[51] L. McLaren, C. A. Beck, S. B. Patten, G. H. Fick, and C. E. Adair, "The relationship between body mass index and mental health," Social Psychiatry and Psychiatric Epidemiology, vol. 43, no. 1, pp. 63-71, 2008.

[52] S. Rasheed and R. T. Woods, "Malnutrition and quality of life in older people: a systematic review and meta-analysis," Ageing Research Reviews, vol. 12, no. 2, pp. 561-566, 2012.

[53] D. B. Menkes, K. Lancaster, M. Grant, R. W. Marsh, P. Dean, and S. A. du Toit, "Vitamin D status of psychiatric inpatients in new zealand's waikato region," BMC Psychiatry, vol. 12, article 68, 2012.

[54] G. Zhang, H. Ding, H. Chen et al., "Thiamine nutritional status and depressive symptoms are inversely associated among older chinese adults," Journal of Nutrition, vol. 143, no. 1, pp. 53-58, 2013.

[55] C. E. Herbison, S. Hickling, K. L. Allen et al., "Low intake of $\mathrm{B}$-vitamins is associated with poor adolescent mental health and behaviour," Preventive Medicine, vol. 55, no. 6, pp. 634-638, 2012.

[56] L. M. Donini, C. Savina, M. Piredda et al., "Senile anorexia in acute-ward and rehabilitation settings," Journal of Nutrition, Health and Aging, vol. 12, no. 8, pp. 511-517, 2008.

[57] L. Perry and S. McLaren, "An exploration of nutrition and eating disabilities in relation to quality of life at 6 months post-stroke," Health and Social Care in the Community, vol. 12, no. 4, pp. 288$297,2004$.

[58] N. G. Choi and D. M. Dinitto, "Psychological distress, binge/ heavy drinking, and gender differences among older adults," American Journal on Addictions, vol. 20, no. 5, pp. 420-428, 2011.

[59] R. M. Puhl and K. D. Brownell, "Confronting and coping with weight stigma: an investigation of overweight and obese adults," Obesity, vol. 14, no. 10, pp. 1802-1815, 2006.

[60] A. G. Wheaton, G. S. Perry, D. P. Chapman, L. R. McKnight-Eily, L. R. Presley-Cantrell, and J. B. Croft, "Relationship between body mass index and perceived insufficient sleep among U.S. Adults: an analysis of 2008 BRFSS data," BMC Public Health, vol. 11, no. 1, article 295, 2011.

[61] W. S. Leslie, C. R. Hankey, and M. E. J. Lean, "Weight gain as an adverse effect of some commonly prescribed drugs: a systematic review," QJM, vol. 100, no. 7, pp. 395-404, 2007.

[62] D. Gallagher, M. Visser, D. Sepúlveda, R. N. Pierson, T. Harris, and S. B. Heymsfieid, "How useful is body mass index for comparison of body fatness across age, sex, and ethnic groups?" American Journal of Epidemiology, vol. 143, no. 3, pp. 228-239, 1996.

[63] A. M. Prentice and S. A. Jebb, "Beyond body mass index," Obesity Reviews, vol. 2, no. 3, pp. 141-147, 2001.

[64] V. Hendrick, L. Altshuler, L. Cohen, and Z. Stowe, "Evaluation of mental health and depression during pregnancy: position paper," Psychopharmacology Bulletin, vol. 34, no. 3, pp. 297-299, 1998.

[65] L. M. Bodnar, K. L. Wisner, E. Moses-Kolko, D. K. Y. Sit, and B. H. Hanusa, "Prepregnancy body mass index, gestational weight gain, and the likelihood of major depressive disorder during pregnancy," Journal of Clinical Psychiatry, vol. 70, no. 9, pp. 1290-1296, 2009.

[66] E. B. Fisher, J. C. Chan, H. Nan, N. Sartorius, and B. Oldenburg, "Co-occurrence of diabetes and depression: conceptual considerations for an emerging global health challenge," Journal of Affective Disorders, vol. 142, supplement, pp. S56-S66, 2012. 


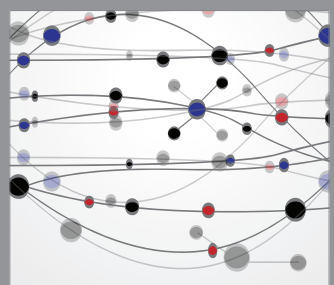

The Scientific World Journal
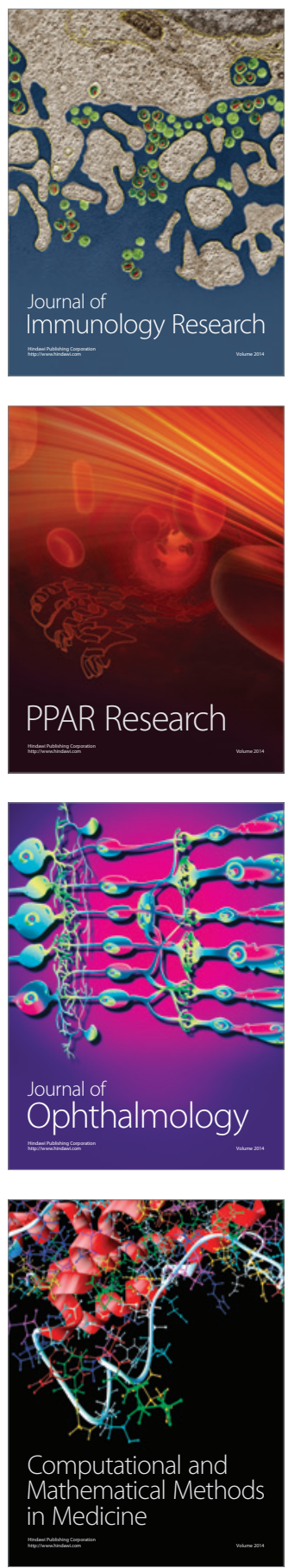

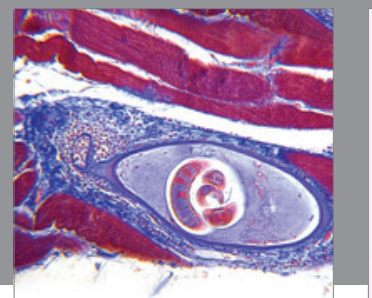

Gastroenterology

Research and Practice
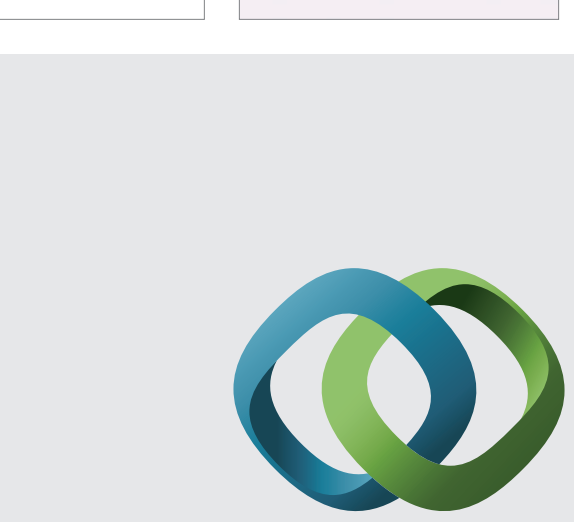

\section{Hindawi}

Submit your manuscripts at

http://www.hindawi.com
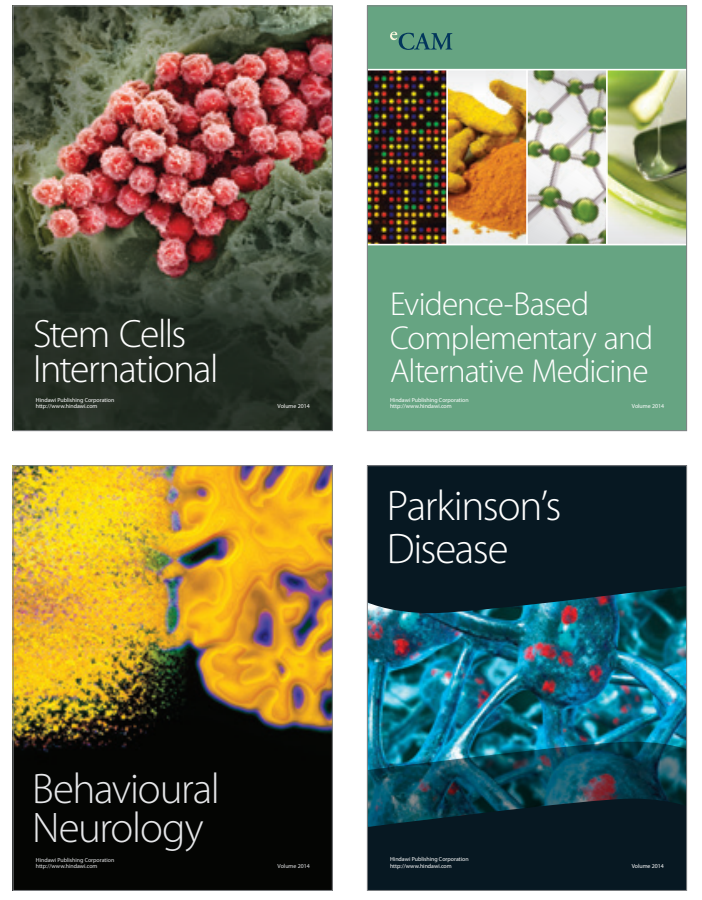
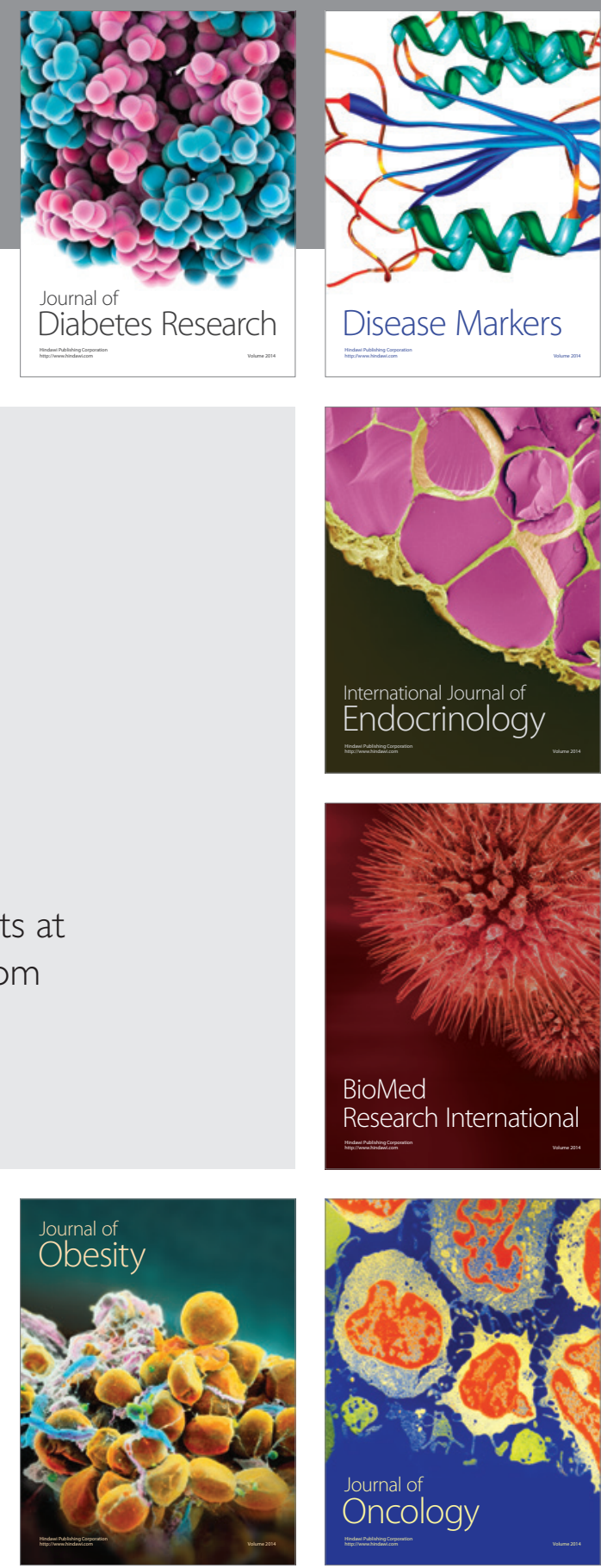

Disease Markers
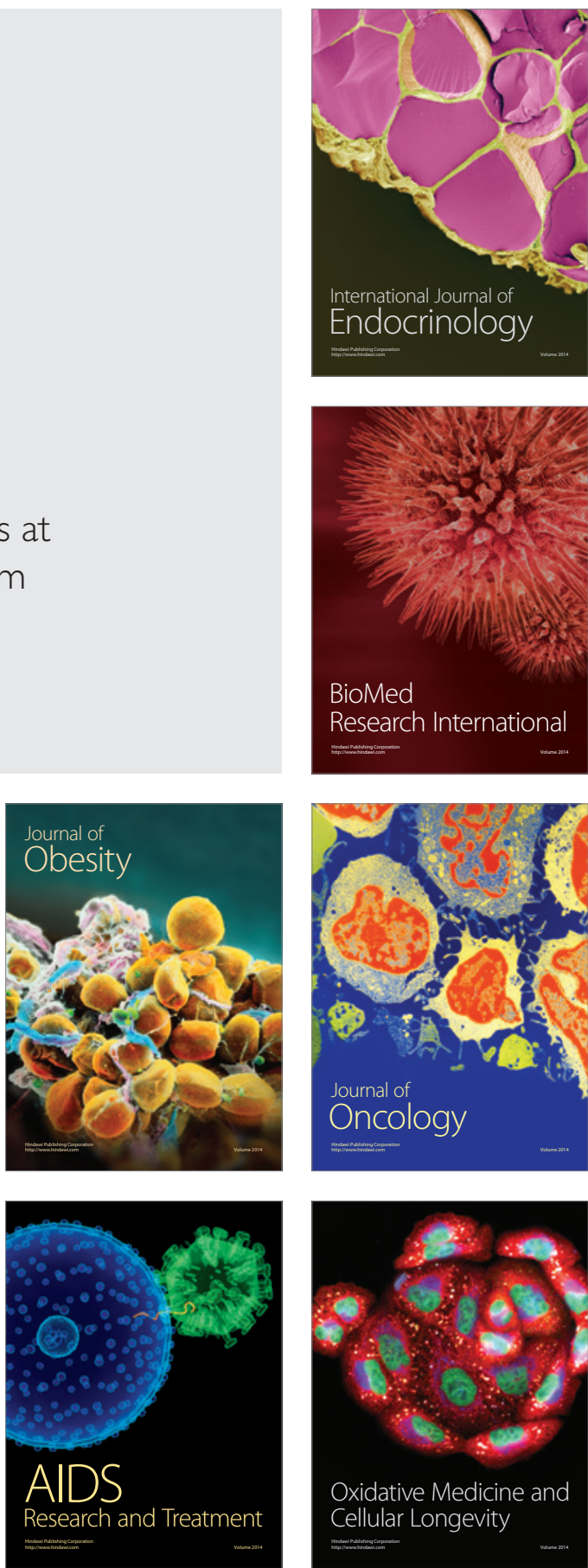